\title{
ORQUESTRAÇÃO VERBAL E MELANCOLIA em Camilo Pessanha
} Álvaro Cardoso Gomes

Resumo: Neste artigo pretendemos analisar as relações entre a poesia e a música em Camilo Pessanha, visando detectar como o poeta expressa estados de alma indefiniveis, entre eles, o da dor cósmica, o da nostalgia e o da melancolia, por meio de uma linguagem sugestiva e evocativa. A musicalidade de seus versos mostra-se como melhor meio para traduzir aquilo que se convencionou chamar de "estado de alma" entre os autores da poesia simbolista.

Palavras-chave: Poesia. Música. Evocação.

\section{INTRODUÇÃo}

$\boldsymbol{U}$ ma das maiores ambições dos poetas simbolistas foi a de alçar a poesia à condição da música. Entre outras razões, porque a linguagem musical é a mais propícia a manifestar os conteúdos da alma ou mesmo estados de espírito que traduzem aquilo que se chamava de "inefável". Camilo Pessanha prende-se a essa tendência, graças à sua poesia altamente sugestiva, que procura expandir sensações por meio do uso adequado do símbolo. Sua linguagem rarefeita, sonora, que explora ao máximo as sinestesias, as aliterações, as assonâncias, está a serviço da manifestação de um estado de espírito bem peculiar que podemos chamar de melancólico. A melancolia, alternando em alguns momentos com a experiência da dor cósmica, que leva à exasperação e desconstrução da identidade, é um modo de ele manifestar um desconforto em relação ao mundo, como se o eu poético vivesse à margem dos eventos, recolhido em si próprio, a observar, distanciado, as imagens que passam sem se fixar diante de seus olhos, deixando-o só e sem substância.

\footnotetext{
* Universidade de São Paulo (USP) e Universidade Santo Amaro (Unisa), São Paulo, SP, Brasil. E-mail: alcgomes@uol.com.br
} 
O estado passivo a que se entrega o poeta traduz a sua perene melancolia, entendida como "um desânimo profundamente penoso, a cessação do interesse pelo mundo externo, a perda da capacidade de amar, a inibição de toda e qualquer atividade" (FREUD apud FRANCHETTI, 2001, p. 98). A melancolia, por sua vez, sempre conviverá com a sensação da dor cósmica, expressa, de maneira intensa e explícita, principalmente no primeiro soneto da trilogia "Caminho". Seja em um caso, seja noutro, o poeta vive à margem do mundo, isolado, fechado em sua intimidade. Nosso intento, pois, é ver como que ele, por meio da linguagem musical, explora esse ensimesmamento, essa dor de viver tão intensa ou mesmo a melancolia.

\section{As CORRESPONDÊNCIAS ENTRE POESIA E MÚSICA}

A busca das correspondências levada a cabo pelos simbolistas justifica o seu esforço em elevar a poesia à condição de música. Por vezes, tal tendência é tão ostensiva que o verso simula uma frase musical, com o sacrifício do significado em prol de significante, como ocorre nestes versos de Cruz e Sousa (1993, p. 454):

Vozes veladas, veludosas vozes,

Volúpia dos violões, vozes veladas,

Vagam nos velhos vórtices velozes

Dos ventos, vivos, vãos, vulcanizadas.

O acúmulo da vibrante "vê" junto à sibilante e a alternância das vogais "a" e "o", mimetizando o som das cordas de um violão, criam a ilusão de uma continuidade sonora, de maneira que o destinatário é atingido, num primeiro momento, mais pelo som do que pelo sentido. O poema atinge um grau máximo de subjetividade, não no sentido de que o poeta expresse um conteúdo individual, mas no sentido de que o poema tem o dom de provocar, como na música, em dado ouvinte/leitor, sensações diferentes a partir dos estímulos sonoros.

Isto porque a música constitui "um modo de representação que se tem por forma e conteúdo o subjetivo em sua objetividade" (HEGEL, 1974, p. 180). A interioridade pura é atingida por dupla negação da exterioridade: quando o corpo vibra, muda de lugar e suprime o espaço; ao tentar recuperar o repouso, suprime o movimento. Decorrente dessa dialética, a música torna-se incapaz de representar a forma dos objetos - não há como lhe atribuir a função mimética. Sua principal missão consiste "não em reproduzir objetos reais, mas em fazer ressoar o eu mais íntimo, a sua mais profunda subjetividade, a sua alma ideal" (HEGEL, 1974, p. 182). Tendo por base tais principios, nota-se que, do mesmo modo que determinado som (ou conjunto de sons) leva à interioridade pura, similarmente, as imagens do poema de Cruz e Sousa, carregadas de sonoridade, soam, para, vibrando, conduzir o leitor ao espaço privilegiado da alma.

A experiência da poesia enquanto música implica radicais transformações da linguagem poética. Primeiro, porque a nota musical é pura sonoridade e permanece como tal em suas múltiplas combinações. Já o fonema, que pode ser considerado também som puro, em suas combinações, dá nascimento a unidades em que o som tem como parceiro o significado. Enquanto puro som, à semelhança das notas musicais, as unidades combinam-se e montam linhas melodiosas 
que imitam a duração. Mas a intervenção dos significados faz que a linha melódica se interrompa: o encanto quebra-se, e a interioridade se dispersa. Vem daí que a poesia necessite acentuar a carga sonora ou, num esforço maior, necessite fazer que a relação entre as palavras se torne tão maleável quanto possivel, de modo a sugerir a continuidade melodiosa. Em realidade, é um artificio, porque tanto o contínuo da melodia quanto o contínuo da poesia "são reconstruções sonoras que se aglomeram além da sensação real, graças ao fluxo e ao torpor da emoção, graças à mistura confusa das lembranças" (BACHELARD, 1972, p. 113).

Há, assim, descontinuidade tanto na música quanto na poesia. Nesta última, como os signos reproduzem os objetos da exterioridade, levando a consciência a interferir no instante da apreensão do real, é de se supor que o descontínuo tenha mais vez que na música. Aproximando a linguagem poética da musical, o simbolista desejava diminuir o grau de descontinuidade, produzindo um discurso que fosse a voz mesma da interioridade. O artifício de que a música se serve para criar o engodo da duração é o da dialética interna entre o perder-se e o reencontrar-se: "a melodia dura porque ela retoma. A melodia joga dialeticamente consigo mesma: perde-se para reencontrar-se" (BACHELARD, 1972, p. 113).

Bachelard refere-se à oposição entre o tema e as variações: se não houver variação, não há mudança (o que resulta na perda da sensação de tempo); se o tema não for retomado, não haverá mudança. É a previsão que instaura na mente a ideia de permanência, daí a retomada do tema como um meio de se criar tal tipo de ilusão. Mas é preciso considerar também o problema do vácuo. Entre uma nota e outra há intervalos temporais, vazios, em que o som teoricamente não deveria existir. Para isso, a música conta com a memória do som, ou com ressonâncias que extrapolam da melodia, um auxiliar da interioridade, tecendo o elo entre os mundos exterior e interior: "quando a nova nota soa, a que a precedeu não desaparece sem um traço; de outra maneira, seriamos incapazes de observar relações entre notas que se seguem às outras" (HUSSERL, 1964, p. 30).

Se o discurso poético é musical, o dos simbolistas é ostensivamente musical, porque além de o poeta desejar representar o princípio da duração, ainda deseja veicular intraduziveis estados de alma. A poesia transforma-se num meio de expressar sensações puras, de evocar mistérios indefiníveis. A linguagem torna-se vaga, imprecisa, pronta a captar impressões fugidias no lusco-fusco, a música do acaso, do crepúsculo, os estados neuróticos outoniços. Explica-se assim a grande obsessão dos simbolistas com a música, não só na referência explícita a instrumentos musicais, como também na apropriação de recursos melodiosos por meio da linguagem poética.

Verlaine e seguidores adotaram um procedimento de aproximação entre a poesia e a música do modo mais literal, na medida em que, em seus poemas, os fonemas se comportavam como se fossem notas musicais. Dessa maneira, tudo se resume a uma questão de pura sonoridade. O poeta não mede esforços para que o verso se transforme numa frase musical. Para tanto, recorre ao auxílio do velho recurso de aliteração, da assonância, do eco, como ocorre, por exemplo, em "Chanson d'automme": "Les sanglots longs/Des violons/De l'automne/Blessent mon coeur/D’une langueur/Monotone"1 (VERLAINE, 1965, p. 72-73).

1 "Os soluços longos/Do violino/Do outono/Ferem meu coração/De um langor/Monótono" (tradução nossa). 
A atuação poética de Verlaine se resumiria a fazer do poema um simulacro de uma melodia, ou conforme Ana Balakian (1969, p. 84), a sua poesia "se converte em música porque se dirige ao ouvido e não por sua função inerente ou por efeito sobre as associações mentais". É o que vem explícito nos primeiros versos de "Art Poétique":

De la musique avant toute chose,

Et pour cela prefere l'Impair

Plus vague et plus soluble dans l'air,

Sans rien en lui qui pèse ou qui pose ${ }^{2}$ (VERLAINE, 1965, p. 326).

O verso ímpar é escolhido, porque instaura uma dissonância, um desequilíbrio, daí advindo a sua imponderabilidade, a sua vaguidez, que o aproxima da música. A importância dada a esse tipo de verso será similar à dada ao verso livre e ao deslocamento da cesura, tão discutido entre os simbolistas. Para Gustave Khan (apud MORETTO, 1989, p. 148), “o verso livre é essencialmente móvel, não deve codificar estrofes. É o acento do impulso e sua adequação à importância, à duração do sentimento evocado ou da sensação a ser traduzida que é sua determinante". Segundo o mesmo autor,

[...] se o verso pseudo-clássico ou o verso romântico fraco não se distingue senão pela rima e pode ser confundido com a prosa, o verso livre, mais fluente, poderá ser confundido com uma prosa poética, ritmada e cantada, com uma espécie de música (KHAN apud MORETTO, 1989, p. 147).

A variação na extensão e medida dos versos evita que o discurso poético se torne lógico pela repetição da mesma medida e, também, lhe dá a imponderabilidade necessária ao surgimento da melodia. Algo idêntico ocorre com o deslocamento da cesura, que, tal como o número ímpar de sílabas no verso, serve para instaurar dissonância e, ao mesmo tempo, para adequar o ritmo à interioridade, na medida em que tanto o número de sílabas quanto a censura serão calculados em virtude do estado de alma que os anima e não o contrário. É o que o crítico Felix Fenéon (apud CASTRO, 1968, p. 23) explica, quando trata da poesia de Jean Moréas:

Moréas repudia toda regra preestabelecida para a tessitura de seus versos, não quer demarcá-los com cesuras equidistantes: aparente revolta, que é se não uma submissão mais fiel às leis da lógica, e que obriga a calcular para cada verso uma correlação entre a posição das sílabas tônicas, o dado temático e os intervalos. Como os mestres impressionistas, que, em vez de preparar sobre sua paleta o valor de uma amostra em uma baixa mistura, onde amolecem as cores, encontram-nas sobre a tela pela ação dos tons puros uns sobre os outros.

A comparação entre o procedimento do poeta e o do pintor impressionista serve para reforçar a ideia de que o ritmo jamais é escolhido a priori e, sim, a posteriori, ou ainda: a forma é totalmente submissa ao dado temático.

Todos esses expedientes utilizados pelos simbolistas visavam, pois, a fazer que a poesia se tornasse musical, seja pela imitação da sonoridade, seja pela rarefação da linguagem que servia para expressar estados de alma indefinidos. É o que veremos a seguir na poesia de Camilo Pessanha.

2 "A música antes de qualquer coisas,/E para isso prefira o Ímpar/Mais vago e mais solúvel no ar,/Sem nada que pese ou que pouse" (tradução nossa). 


\section{A orguestração verbal em Camilo Pessanha}

Entre os simbolistas de lingua portuguesa, quem mais se distinguiu nessa procura de associação entre a linguagem verbal e a musical foi Camilo Pessanha. Não bastasse ele se utilizar da musicalidade para evocar estados de espírito indefinidos, num conjunto de alguns poemas, faz referências explícitas a instrumentos musicais, por meio dos quais expressa a sua melancolia, a sua dor de viver. Para começar, lembrariamos de um poema emblemático, em que há o princípio de que um estímulo sonoro desperta, sinestesicamente, sensações de outra ordem no ouvinte/leitor:

\section{Fonógrafo}

Vai declamando um cômico defunto.

Uma plateia ri, perdidamente,

Do bom jarreta... E há um odor no ambiente

A cripta e a pó, - do anacrônico assunto.

Muda o registo, eis uma barcarola:

Lírios, lírios, águas do rio, a lua.

Ante o Seu corpo o sonho meu flutua

Sobre um paul, - extática corola.

Muda outra vez: gorjeios, estribilhos

Dum clarim de oiro - o cheiro de junquilhos,

Vivido e agro! - tocando a alvorada...

Cessou. E, amorosa, a alma das cornetas

Quebra-se agora orvalhada e velada.

Primavera. Manhã. Que eflúvio de violetas! (PESSANHA, 1969, p. 187-188).

O aparelho de reprodução sonora, o fonógrafo, libera sonoridades que evocam imagens variadas que, por sua vez, servem para marcar a passagem do tempo. Pessanha segue aqui a lição simbolista, no que se refere ao uso do símbolo, entendido como um meio de expressar uma sensação que, por sua vez, desperta uma sensação de outra espécie, de modo a prolongar as emoções, como bem observa o crítico Saint Antoine (apud GOMES, 1994, p. 125):

Prossigamos: a palavra sugerir tem dois sentidos. De início, será despertar, indicar sem designar. É a alusão, e Mallarmé diz: "Creio que é preciso que haja somente alusão”. Em segundo lugar, será: prolongar ao máximo uma emoção. É neste sentido que se qualifica uma poesia como sugestiva; dir-se-á igualmente que a música é a arte sugestiva por excelência.

Esta emoção prolongada pode nascer - o gênio do poeta auxiliando - da expressão simples. O mais comum é ela resultar da imagem; deste modo, a sensação que se desperta será prolongada e reforçada por uma impressão de ordem diferente; por exemplo, uma emoção íntima refletida e universalizada na natureza ambiente, ou reciprocamente, um cenário exterior animado repentinamente pela paixão do poeta. Os poetas simbolistas frequentemente recorreram a este procedimento de sugestão, mas não a inventaram, e é possível encontrar sem dificuldade, em Victor Hugo, o equivalente do verso que, em Verlaine, "faz soluçar de êxtase os chafarizes". 
Na primeira estrofe, a voz do palhaço defunto, se provoca risos na plateia, por outro lado, dá ensejo a que surja um odor de "cripta e pó" naquele ouvinte que não pertence ao grupo de espectadores do palhaço. Ou seja, a sensação auditiva desperta nele sensações olfativas e imagens ligadas à morte, porque o assunto se tornou anacrônico. A circunstancialidade do humor, de modo geral, ligada a determinada época e a determinado círculo, pode implicar seu envelhecimento precoce. O que é considerado cômico por um conjunto de pessoas, pertencentes a certo meio, perde essa prerrogativa para um sujeito que a ele não pertence. É o que observa Bergson (1924, p. 11), ao tratar dos limites do riso:

Notre rire est toujours le rire d'un groupe. Il vous est peut-être arrivé, en wagon ou à une table d'hôte, d'entendre des voyageurs se raconter des histoires qui devaient être comiques pour eux puisqu'ils en riaient de bon cœur. Vous auriez ri comme eux si vous eussiez été de leur société. Mais n'en étant pas, vous n'aviez aucune envie de rire $^{3}$.

A mudança de registro na segunda estrofe significa que, agora, em vez de uma sessão cômica, se dá a audição de um tipo de música, a barcarola. O processo de prolongamento de emoções tem continuidade, na medida em que o estímulo sonoro ativa sensações visuais de um paul, de lírios, das águas, da lua e de uma figura emblemática que é Ofélia, ante quem se manifesta o sonho do sujeito. Neste caso, há uma forte identificação entre o ritmo da música e o fluir das águas:

[...] a música flui mansamente [...], como a calma do rio; ou ainda, a música, em seu aspecto anti-intelectual, estabelece uma relação bastante clara com a transparência vazia do líquido, remetendo-nos ao devaneio, produtor de imagens sempre femininas, quando o devaneio está sob o signo da anima (GOMES, 1977, p. 47).

Aliás, Bachelard (1973, p. 114-115), em L'Eau et les rêves, faz referência a essa morte essencialmente feminina representada pela heroína shakesperiana:

Pendant les siècles, elle apparaitra aux rêveurs et aux poètes, flottant sur son ruisseau, avec seus fleurs et sa chevelure étalée sur l'onde. Elle sera l'occasion d'une des synecdoques poétiques les plus claires. Elle será une chevelure flottante, une chevelure dénouée par les flots ${ }^{4}$.

Sucede-se ao som da barcarola o de um "clarim de oiro", cujo som, sinestesicamente, estridente e dourado, remete ao perfume acre dos junquilhos e à imagem do nascer do sol. E, por fim, a corneta substitui o clarim e, como tal, liga-se às imagens da cor roxa das violetas e, por extensão, da manhã e da primavera.

Não é difícil de ver também nessa sequência de sonoridades propiciadas pelo fonógrafo, que evoca imagens de ordens e sensações diversas, principalmente as olfativas e visuais, um simulacro da passagem do tempo. O poema figura, em sua plasticidade, a duração temporal e, por extensão, manifesta o fenômeno da

\footnotetext{
3 "Nosso riso é sempre o riso de um grupo. Já vos deve ter acontecido, viajando de trem ou sentado à mesa de um hotel, de ouvir viajantes contarem histórias que deveriam ser cômicas porque eles riam à vontade. Vós teríeis rido se vós pertencêsseis à sociedade deles. Contudo, se não pertencêsseis, vós não teríeis vontade alguma de rir" (tradução nossa).

4 "Durante os séculos, ela apareceu aos sonhadores e poetas, flutuando em seu riacho, com suas flores e sua cabeleira desatada sobre as ondas. Ela será o motivo de uma das sinédoques poéticas mais claras. Ela será uma cabeleira flutuante, uma cabeleira desfeita pela torrente" (tradução nossa).
} 
transitoriedade. Na primeira estrofe, a lembrança da morte liga-se à visualização da noite, na segunda, as imagens da lua e da cor branca fazem lembrar a noite, mas agora iluminada, já prenunciando o que virá na terceira estrofe que é a alvorada, de coloração dourada, anunciada pela voz do clarim. E na última estrofe, o dia se oferece de vez, irmanando-se à manhã e à primavera. O estímulo musical, manifesto por diferentes vozes, desperta sensações, contudo, para se evitar a dispersão das sensações e emoções, na medida em que o poeta as escolhe de maneira mais ou menos aleatória, a sugestão do tempo que flui é que dará unidade temática ao soneto.

Em outro poema, Camilo Pessanha (1969, p. 237-238) explora algo similar, mas o estímulo, nesse caso, é suscitado pela melodia de um violoncelo:

Chorai arcadas

Do violoncelo!

Convulsionadas,

Pontes aladas

De pesadelo...

De que esvoaçam,

Brancos, os arcos...

Por baixo passam,

Se despedaçam,

No rio, os barcos.

Fundas, soluçam

Caudais de choro...

Que ruínas, (ouçam)!

Se se debruçam,

Que sorvedouro!...

Trêmulos astros,

Soidões lacustres...

- Lemes e mastros...

E os alabastros

Dos balaústres!

Urnas quebradas!

Blocos de gelo...

- Chorai arcadas,

Despedaçadas,

Do violoncelo.

O violoncelo evoca vozes que, à semelhança das arcadas dilaceradas, sentem a proximidade da morte. A melodia possui ritmos diferentes que conduzem a estados imagéticos também diferentes, a cada momento evocativo dos grupos de versos. Ao se utilizar do vocativo, o poeta personaliza o instrumento e dá-lhe estatuto mais que explícito de metáfora do ser humano: o violoncelo é o coração inominado, o coração cujas fibras vibram, provocando a melodia dissonante, prenúncio de morte.

O poema tem um caráter icônico, quando se verifica que, em sua verticalidade, as estrofes mimetizam o corpo de um violoncelo. A começar pelo fato de que as quatro sílabas do verso correspondem às quatro cordas do instrumento, e os parêntesis em meio do poema são a imagem dos orificios da caixa de ressonância. Podemos ainda ver o leitor virtual, o seu olhar, como simulacro do arco que 
corre as cordas do violoncelo-poema, liberando a melodia que se atualiza a cada leitura. O ritmo do poema oscila de maneira uniforme entre grupos de versos com duas tônicas fortes e versos com uma tônica dominante, organizando um movimento dual.

A oscilação do ritmo ocorre também no extrato sonoro fonemático: as vogais alternam os sons abertos (que dominam no poema) com sons fechados, e essa alternância corresponde à do sintagma dominante: "arcadas do violoncelo", o par feminino/masculino, interior/exterior, parte/todo, que, produzindo a melodia, provocará o sentimento de dor intensa, representada por um mundo de pesadelos. Assim, se o poema iconiza, em sua forma, o violoncelo, os versos, as estrofes e o ritmo iconizam uma melodia, desde os sons mais puros até sua arrumação numa pauta, passando pelos movimentos, sugestões de temas e variações, que se oferecem na abertura e são retomados de modo levemente alterado no final.

Mas nos detenhamos com mais vagar na estrutura poemática, que é um simulacro da estrutura de uma melodia. A água torna-se presente no texto sob cinco caracterizações diferentes: rio, caudais de choro, sorvedouro, lago e gelo. Elas se identificam aos movimentos da música que lhes são correspondentes, ilustrando diferentes motivos de uma melodia: o fluir contínuo, espaçados soluços, o turbilhão confuso, a calma mortal e estanque e a solidificação fragmentada do final. O fluir do rio até o lago e o gelo, passando pelo sorvedouro, cria a imagem da morte, sugerida pelo violoncelo despedaçado. Assim, o processo imagético do poema se oferece a partir de referência a uma melodia metaforizada pelo choro, que produz o pesadelo evocador de um rio, em que boiam fragmentos de barcos. A melodia explicitada na primeira estrofe ganha logo estatuto de melodia de palavras, quando ela se interioriza por meio do ritmo, da rima e, sobretudo, por meio das aliterações, presentes nas vibrantes, nas líquidas, no jogo de vibrantes e dentais, como em "trêmulos astros", "alabastros dos balaústres". Se no caso das sibilantes e liquidas, o arco corre/escorre sobre as cordas, nestes últimos casos, há como que um vibrar das cordas, provocando frissons, calafrios.

A água serve de fio condutor deste esfacelamento do mundo, que corresponde à perda da unidade do "eu", cuja dissolução interior se dá pela contemplação/audição da corrente musical. O processo de dor tem correspondência com o processo melodioso, a tal ponto que tudo converge para a terceira estrofe do poema, em que a imagem de sorvedouro é um núcleo em perene movimento. Contudo, esse movimento constitui uma espécie de moto-perpétuo, a tradução da eterna dor humana, ao modo schopenhauer sem fim e sem objetivo. O tanger do instrumento musical assemelha-se ao choro, pranto que evoca a morte. A música é o elemento que suscita o sonho, o pesadelo, é a ponte, imagem que se reitera no arco do violoncelo, no formato dos barcos e na própria palavra "(b) arco". A ponte é a música em sua variada fluência, que transporta o "eu" a uma realidade sombria, dissonante. Produção do delírio, o mundo resulta da matéria virtual, a água, que, em suas múltiplas formas, reinventa o espaço do sonho caótico. Neste clima de pesadelo, a melodia intensifica-se com o fluir aquático: os barcos fazem de arcos junto às pontes que, por sua vez, substituem o violoncelo - o jogo de espelhos em que as metáforas encontram imagens correspondentes por meio da livre associação. A fusão música/fluir das águas intensifica-se, no instante em que o movimento se torna mais agudo: a dor aumenta (ao 
invés do choro, "caudais de choro"). O núcleo do poema é, de modo paradoxal, composto de ruínas. Essa decomposição é sugerida pela imagem do sorvedouro, como reflexo da vida interior. Inclusive, os parêntesis iconicamente sugerem a interioridade. Ruínas sonoras, o recolhimento mórbido que conduz ao abismo.

Por isso, percebe-se a importância do ritmo em todo o poema: nas duas primeiras estrofes, a fluência, nas duas últimas, a fragmentação do gelo. E como intervalo, o círculo do labirinto. O sorvedouro, metáfora do ensimesmamento, é o abraço letal do inconsciente, que engolfa os seres e os faz retomar à sua origem pré-formal. Tanto que a próxima estrofe desenha uma calmaria: desaparecem os verbos e, numa atmosfera de morte, em silêncio, boiam astros a morrer, um lago de águas paradas e sombrias, fragmentos de barcos, os lemes e mastros, pedaços da sólida ponte - os alabastros dos balaústres. Apenas sinédoques, conjuntos desirmanados a fingir de realidade física ou de espólio dessa mesma realidade física: astro morto, água morta, matéria fria - objetos que instauram arremedo de linguagem, porque "o verbo é a condição indispensável a todo o discurso: e onde ele não existe, pelo menos de maneira virtual, não é possivel dizer-se que há linguagem" (FOUCAULT, 1966, p. 131). Assim como as frases se tornam nominais, mimetizando o universo sem discurso, puro silêncio, caos, também a música radicaliza sua ação, ao fazer que os fonemas-notas musicais se reduzam a puras vibrações, antessala do silêncio: "trêmulos astros", "lacustres", "alabastros", "balaústres".

Desfaz-se o encantamento: o excesso de dor leva a um paroxismo que rompe a ordem natural e instaura a fragmentação do mundo. Restam, ao cabo, as imagens funerárias das urnas, vazias de segredos, pois estão quebradas. O seu conteúdo são blocos de gelos, a água que não mais se movimenta e atingiu a perfeição mórbida do cristal. Mundo cristalizado, translúcida forma informe, a arcada despedaçada de um violoncelo, o fluir estanque da melodia. Nada mais há senão o silêncio sepulcral, contraste antinômico do som - a alma regressa a um estágio anterior à linguagem, e o balbucio das frases nominais cede terreno a um estado virtual, anterior à criação do Cosmo. A água morta é impotente para criar o devaneio: a qualidade gelada, recolhimento invernal, impede o fluir contínuo, o vaivém embalador, acariciador do sonho. A convulsão do início cede lugar ao despedaçamento do fim. O poema cessa como cessa a música, fazendo que a evocação melodiosa de imagens deixe de acontecer.

Em "Viola chinesa", Camilo Pessanha faz referência a outro instrumento de cordas, a viola. Mais conhecido como "erhu", é um instrumento musical originário da China, com duas únicas cordas, tocado com o auxílio de um arco (normalmente feito com crina de cavalo, como nos arcos de violinos comuns). Devido à sua simplicidade, se a compararmos com o violoncelo, a viola caracteriza-se pela produção de uma melodia menos complexa e monótona, pelo menos, para os padrões ocidentais, o que terá como consequência a produção, no espírito do sujeito, de um estado de espírito muito especial:

\section{Viola chinesa}

Ao longo da viola morosa

Vai adormecendo a parlenda,

Sem que, amadornado, eu atenda

A lengalenga fastidiosa. 
Sem que o meu coração se prenda,

Enquanto, nasal, minuciosa,

Ao longo da viola morosa,

Vai adormecendo a parlenda.

Mas que cicatriz melindrosa

Há nele, que esta viola ofenda

E faz que as asitas distenda

Numa agitação dolorosa?

A longo da viola, morosa... (PESSANHA, 1969, p. 241-242).

O som da viola provoca no sujeito a sonolência que é responsável por fazer que ele deixe de prestar atenção à lenga-lenga. O clima de morbidez, de tédio, é acentuado pelo caráter nasal do instrumento que faz que o sujeito, ao se desligar da realidade exterior, representado pela parlenda, penetre cada vez mais fundo em sua interioridade, representada, por sua vez, pelo coração doente. O efeito final do som da viola sobre ele é o despertar da dor que já estava incubada em seu íntimo. O instrumento musical só faz atualizar algo que existia nele enquanto potencialidade, o que é visível no uso da metáfora da cicatriz. Há, pois, uma analogia ou mesmo uma correspondência entre os mundos exterior e interior, aquele metaforizado pela música, este, pelo coração. A monotonia do som da viola corresponde a um sentimento de dor indefinivel, que pode ser identificado ao estado melancólico por excelência.

No poema "Ao longe os barcos de flores", a musicalidade manifesta-se agora por meio de um instrumento de sopro:

Só, incessante, um som de flauta chora,

Viúva, grácil, na escuridão tranquila,

- Perdida voz que de entre as mais se exila,

- Festões de som dissimulando a hora.

Na orgia, ao longe, que em clarões cintila

E os lábios, branca, do carmim, desflora...

Só, incessante, um som de flauta chora,

Viúva, grácil, na escuridão tranquila.

E a orquestra? E os beijos? Tudo a noite, fora,

Cauta, detém. Só modulada trila

A flauta flébil... Quem há de remi-la?

Quem sabe a dor que sem razão deplora?

Só, incessante, um som de flauta chora... (PESSANHA, 1969, p. 239-240).

Pessanha serve-se neste poema de um "correlativo objetivo", como o entendia Eliot (1961, p. 145):

[...] o único meio de exprimir emoção sob a forma de arte consiste em achar um "correlativo objetivo"; noutras palavras, um conjunto de objetos, uma situação, uma cadeia de acontecimentos, que constituirá a fórmula daquela emoção particular; de tal maneira que, quando ocorrerem fatos exteriores, que devem culminar numa experiência sensorial, a emoção seja imediatamente vocada. 
O "correlativo objetivo" é a flauta que representa metaforicamente o sujeito em sua intimidade. O poema constitui um rondel, forma literária que se caracteriza pela repetição - no caso, o verso emblemático "Só incessante, um som de flauta chora" -, em que se nota a mimetização do som do instrumento musical pelo recurso da aliteração, construída por meio das sibilantes e da alternância entre sílabas fechadas e nasais e as abertas. A ideia de solidão da flauta é reforçada pela palavra "viúva" e pelo verso "perdida voz que entre as mais se exila". Ou seja, a flauta soa isolada dos outros instrumentos da orquestra, o que a leva também a um distanciamento da "orgia", dos "beijos".

A imagem da flauta concebida como viúva, sugere, por extensão, a proximidade da morte, como se vê no estranho verso "E os lábios, branca, do carmim desflora". O sentido dele seria: "(a flauta) desflora (ou descora) do carmim, brancamente, os lábios", ou seja, ao se tocar o instrumento, o esforço faz que os lábios percam o colorido rubro, desse modo, sugerindo a ideia de morte. A cor branca, sinônimo de vazio, de ausência, opõe-se à cor vermelha, sinônimo de vida, remetendo-nos à ideia de perda que se acentua, na penúltima estrofe com a imagem sonora da fraqueza da voz, "flauta flébil", sugerida pela presença insistente das líquidas, já presentes na imagem anterior "Só modulada trila". E, para coroar esse processo pela musicalidade, Pessanha habilmente serve-se de um recurso musical diferenciado, no fragmento "Quem há de remi-la?", em que o verbo "remir", precedido pela preposição "de", faz lembrar as notas em sua escala (dó, ré, mi, lá), com a ausência das notas fá e sol. Esta escala deformada serve para sugerir um salto, um último suspiro, lamento da voz feminina, separada dos demais instrumentos da orquestra e que representa, no caso, o isolamento, a solidão do próprio sujeito poético.

\section{Conclusão}

Dos poemas analisados, acreditamos que pelo menos dois - "Viola chinesa" e "Ao longe os barcos de flores" - manifestam, de maneira bem clara, o princípio de os versos servirem para expressar um isolamento, uma dor indefinida, que poderiam ser identificados à melancolia, assim explicada por Starobinski (2016, p. 429):

Nos confins do silêncio, no sopro mais fraco, a melancolia murmura: "Tudo está vazio! Tudo é vaidade!”. O mundo é inanimado, atacado de morte, aspirado pelo nada. O que foi possuído se perdeu. O que foi esperado não ocorreu. O espaço está despovoado. Por todo lado entende-se o deserto infecundo. E se um espírito paira acima dessa extensão, é o espírito da constatação desolada, a negra nuvem da esterilidade, de onde jamais brotará o raio de um fiat lux. Do que a consciência contivera, o que resta? Apenas algumas sombras. E talvez o vestígio dos limites que faziam da consciência um receptáculo, um continentecomo a muralha extinta de uma cidade devastada. Mas para o melancólico a vastidão, nascida da devastação, é por sua vez abolida. E o vazio torna-se mais exíguo que a mais estreita masmorra.

Chamamos a atenção, sobretudo, para o seguinte trecho: "o espírito da constatação desolada, a negra nuvem da esterilidade, de onde jamais brotará o raio de um fiat lux". Parece que cabe como uma luva na expressão da melancolia experimentada por Camilo Pessanha. A expressão musical serve, pois, como 
veículo para a manifestação de um estado de espírito dolente, passivo diante da existência. O resultado é a dor entendida em duas dimensões: como cósmica, responsável pela fragmentação do sujeito, ou como manifestação de uma interioridade dominada pela melancolia.

\section{Verbal orchestration and melancholy in Camilo Pessanha}

Abstract: In this article we intend to analyze the relationship between poetry and music in Camilo Pessanha, with a view to detecting how the poet expresses indefinable states of soul, among them, that of cosmic pain, nostalgia and melancholy, for suggestive and evocative language. The musicality of his verses shows itself as the best way to translate what has been called the "state of soul" among the writers of Symbolist poetry.

Keywords: Poetry. Music. Evocation.

\section{REFERÊNCIAS}

BACHELARD, G. La dialéctique de la durée. Paris: PUF, 1972.

BACHELARD, G. L'eau et les rêves. Paris: José Corti, 1973.

BALAKIAN, A. El movimiento simbolista. Madrid: Guadarrama, 1969.

BERGSON, H. Le rire: essai sur la signification du comique. Paris: Éditions Alcan, 1924.

CASTRO, E. Prefácio de Oaristos. In: CASTRO, E. Obras poéticas de Eugénio de Castro. Coimbra: Parceria A. M. Pereira, 1968. v. 1.

CRUZ E SOUSA. Missal/Broquéis. São Paulo: Martins Fontes, 1993.

ELIOT, T. S. Hamlet. In: ELIOT, T. S. Selected essays. London: Faber \& Faber, 1961.

FOUCAULT, M. As palavras e as coisas. Lisboa: Portugália, 1966.

FRANCHETTI, P. Nostalgia, exílio e melancolia. São Paulo: Edusp/Fapesp, 2001.

GOMES, A. C. A metáfora cósmica em Camilo Pessanha. São Paulo: FFLCH-USP, 1977.

GOMES, A. C. A estética simbolista. 2. ed. ampl. São Paulo: Atlas, 1994.

HEGEL. Estética: poesia e música. 2. ed. Lisboa: Guimarães Editores, 1974.

HUSSERL, E. The phenomenology of internal time-consciousness. Bloomington: Indiana University Press, 1964.

MORETTO, F. Caminhos do decadentismo francês. São Paulo: Perspectiva, 1989. PESSANHA, C. Clepsidra e outros poemas. Lisboa: Ática, 1969.

STAROBINSKI, J. A tinta da melancolia: uma história cultural da tristeza. São Paulo: Cia. das Letras, 2016.

VERLAINE, P. Oeuvres poétiques complètes. Paris: Gallimard, 1965. 